\title{
Study of Peroxisome Proliferator Activated Receptor $\gamma$ Pro12Ala Polymorphism in Women with Polycystic Ovary Syndrome
}

\author{
${ }^{1}$ Monika Garg, ${ }^{2}$ Anju Jain, ${ }^{3}$ Binita Goswami, ${ }^{4}$ Manju Puri
}

\begin{abstract}
Introduction: Peroxisome proliferator activated receptor- $\gamma$ (PPAR- $\gamma$ ) and its polymorphisms have an important role in polycystic ovary syndrome (PCOS), pathogenesis of which concentrates mainly around insulin resistance.
\end{abstract}

Aims and objectives: To identify PPAR- $\gamma$ Pro12Ala Polymorphism in subjects with PCOS and controls along with an estimation of PPAR $\gamma$ levels and to correlate these with biochemical and anthropometric parameters of insulin resistance.

Materials and methods: A hospital-based case control study was conducted in 50 diagnosed cases of PCOS (15 to 45 years of age), as per revised Rotterdam criteria along with 50 age-matched healthy controls. PPAR- $\gamma$ levels were estimated using sandwich enzyme-linked immunosorbent assay (ELISA). Polymorphism was detected through DNA extraction from whole blood followed by polymerase chain reaction (PCR) and restriction fragment length polymorphism (RFLP). Statistical analysis was done using Statistical Package for the Social Sciences (SPSS) version 16 employing independent sample t-test for intergroup comparison of means and Pearson's correlation coefficient for correlation analysis. Categorical data analysis for polymorphism was done using chi-square test. ROC analysis was done for comparison between various markers.

Results and conclusion: Peroxisome proliferator activated receptor $\gamma$ (PPAR- $\gamma$ ) Pro12Ala polymorphism analysis revealed a higher proportion of Pro/Pro homozygotes (78\%) in contrast to a lower proportion of Pro/Ala heterozygotes $(22 \%)$ in cases. Also, Pro/Pro homozygotes were associated with a higher proportion of insulin resistance $(86.7 \%)$ and obesity (83.8\%) as compared to Pro/Ala heterozygotes in PCOS cases. PPAR-y levels were significantly reduced in cases [13.16 $(11.78-17.08) \mathrm{ng} / \mathrm{mL}$ ] as compared to controls [16.05 (12.07-33.0) ng/mL]. This strengthens the fact that insulin sensitivity is related to enhanced PPAR-y expression. ROC analysis revealed PPAR-y to be a better indicator of

${ }^{1}$ Senior Resident, ${ }^{2}$ Director; Professor and Head, ${ }^{3}$ Associate Professor, ${ }^{4}$ Director; Professor

${ }^{1-3}$ Department of Biochemistry, Lady Hardinge Medical College, New Delhi, India

${ }^{4}$ Department of Obstetrics and Gynaecology, Lady Hardinge Medical College, New Delhi, India

Corresponding Author: Monika Garg, Senior Resident, Department of Biochemistry, Lady Hardinge Medical College, New Delhi, India, Phone: +919868862567, e-mail: mg.monikagarg25@gmail.com
PCOS (AUC $=0.605)$. To conclude, this study is suggestive of a protective role of Pro/Ala (CG) heterozygotes in PCOS and their possible association with insulin resistance and obesity.

Keywords: Insulin resistance, Polycystic ovary syndrome (PCOS), PPAR-y polymorphism.

How to cite this article: Garg M, Jain A, Goswami B, Puri M. Study of Peroxisome Proliferator Activated Receptor $\gamma$ Pro12Ala Polymorphism in Women with Polycystic Ovary Syndrome. Indian J Med Biochem 2018;22(2):126-131.

Source of support: Nil

Conflict of interest: None

\section{INTRODUCTION}

Infertility, a major problem in the urbanized world, (mostly anovulatory infertility) is most commonly caused by PCOS. ${ }^{1}$ It is characterized by oligo-ovulation or anovulation, hyperandrogenemia and polycystic ovaries $(\geq 12$ cysts) on ultrasonography. ${ }^{2}$ The diagnosis using revised Rotterdam criteria 2003, shows its worldwide prevalence to be between 5 to $10 \%{ }^{1}$

Multiple risk factors associated with PCOS like inflammation, vitamin D deficiency, hormonal imbalance, genetic predisposition, etc., lead to hyperandrogenemia and insulin resistance. ${ }^{3,4}$ Insulin Resistance is seen in 30 to $40 \%$ women with PCOS and hyperinsulinemia is observed in about 50 to $70 \%$ of women with PCOS. ${ }^{5,6}$ This occurs as a result of serine phosphorylation of insulin receptors on cells, which inhibits their tyrosine kinase activity. This leads to a reduction in GLUT-4 glucose transporters and hence reduced glucose uptake in peripheral tissues. ${ }^{7}$ Recent researchers have demonstrated an improvement in most of the PCOS symptoms merely by decreasing the insulin resistance.

One of the most promising insulin-sensitizing drugs is thiazolidinediones (TZD) which act through glitazone receptors, more commonly referred to as the Peroxisome PPAR- $\gamma .{ }^{8,9}$ PPAR- $\gamma$ is further divided into PPAR- $\gamma 1$, PPAR- $\gamma 2$ and PPAR- $\gamma 3 .{ }^{10}$ Among these, PPAR- $\gamma 2$ is expressed in adipose tissues and is involved in adipocyte differentiation, fat deposition in adipose tissues, improving insulin sensitivity and regulation of ovarian steroidogenesis. $^{11}$ 
Out of the various PPAR- $\gamma$ polymorphisms, PPAR- $\gamma$ Pro12Ala polymorphism is most frequently studied. This polymorphism involves a missense mutation of CCA to GCA in codon 12 of exon B of PPAR- $\gamma$ gene located on chromosome 3p25, leading to the substitution of Proline to Alanine resulting in an excessive expression of PPAR- $\gamma 2$. This, in turn, causes stimulation of insulin sensitivity by promoting insulin action in adipose tissues. ${ }^{12-15}$

\section{MATERIALS AND METHODS}

A hospital-based observational case-control study was conducted in the Department of Biochemistry in collaboration with the Department of Obstetrics and Gynaecology, Lady Hardinge Medical College and Smt. Sucheta Kriplani Hospital, New Delhi, after being approved by the institutional ethical committee.

The study population consisted of 50 diagnosed cases of PCOS in the age group of 15 to 45 years, as per revised Rotterdam criteria along with 50 age-matched healthy volunteers.

Women with related hormonal disorders like congenital adrenal hyperplasia (CAH), Cushing's syndrome and androgen-secreting tumors and patients on treatment with oral contraceptive pills (OCP) and high dose androgens were excluded from the study.

Bilingual written informed consent was obtained from the study subjects. Detailed history and clinical examination of study subjects was also carried out.

Fasting venous blood samples $(5 \mathrm{~mL})$ was collected from the subjects on day 2 to 5 of the menstrual cycle after overnight fasting. Serum was separated and processed for routine investigations like fasting plasma glucose and lipid profile by clinical chemistry autoanalyzer-Beckman Coulter AU-680 using standard reagents/ kits from Randox (United Kingdom) and Beckman (United States). ELISA did special investigations [PPAR- $\gamma$, dehydroepiandrosterone sulfate (DHEAS), and sex hormone-binding globulin (SHBG)].

Hormonal estimation [luteinizing hormone (LH), folliclestimulating hormone (FSH), prolactin, testosterone, insulin, thyroid-stimulating hormone (TSH)] by electrochemiluminescent immunoassay (ECLIA) or clinical laboratory improvement amendments (CLIA) was done on Cobas e411
(Switzerland). Wholeblood was used to extract deoxyribonucleic acid (DNA) by commercially available kits from Qiagen (Netherlands) followed by PCR targeting PPAR- $\gamma$ gene, using following primers.

\section{Forward Primer}

\section{5' GCATGGATCCCAATGC 3' (18 bp)}

\section{Reverse Primer}

5'GATATGTTTGCAGACAGTGTATCAGTGAAGGA ATCGCTTTCCG 3' (43 bp) polymorphism in PPAR- $\gamma$ gene was detected using RFLP by using restriction enzyme BstUI. The resolution was done on $2.5 \%$ agarose gel electrophoresis

The data were analyzed statistically by using SPSS ver. 16. Intergroup comparison of biochemical parameters between cases and controls was done using independent sample ' $t$ ' test (for parametric data) and the Mann Whitney $U$ test (for non-parametric data). The $\mathrm{p}<0.05$ was considered as statistically significant. Correlation analysis of the quantitative data was done using Pearson's correlation coefficient (for parametric data) and the Spearman correlation coefficient (for non-parametric data). Categorical data analysis for the study of PPAR- $\gamma$ polymorphism was done using chi-square test with odd's ratio as the risk estimate.

\section{RESULTS}

Following the inclusion criteria, 50 cases of PCOS along with 50 age-matched healthy controls were enrolled in the study. Mean age of the study population was 26.3 \pm 4.7 years. Baseline characteristics of PCOS cases and controls are shown in (Table 1).

Mean weight, BMI, waist circumference and waist-tohip ratio were significantly higher in cases as compared to controls $(\mathrm{p}<0.05)$. Of the various biochemical parameters studied, serum triglyceride was found to be significantly higher in cases as compared to controls (Table 2). No statistically significant difference was seen in the fertility profile parameters and glycaemic indicators (Table 2) between cases and controls. Among the indicators of

Table 1: Baseline characteristics of the study population

\begin{tabular}{llll}
\hline Variable & Cases $(n=50)($ Mean \pm S.D.) & Controls $(n=50)($ Mean \pm S.D.) & $p$ value \\
\hline Age $($ years $)$ & $25.7 \pm 4.7$ & $26.9 \pm 4.7$ & 0.21 \\
Height $(\mathrm{cm})$ & $153.5 \pm 5.3$ & $153.3 \pm 4.5$ & 0.86 \\
Weight $(\mathrm{Kg})$ & $64.6 \pm 12.2$ & $54.7 \pm 9.8$ & $<0.001^{*}$ \\
BMI $\left(\mathrm{kg} / \mathrm{m}^{2}\right)$ & $27.38 \pm 4.81$ & $23.26 \pm 3.97$ & $<0.001^{*}$ \\
WC $(\mathrm{cm})$ & $88.66 \pm 1.21$ & $73.04 \pm 9.88$ & $<0.001^{*}$ \\
WHR & $1.01 \pm 0.28$ & $0.82 \pm 0.07$ & $<0.001^{*}$ \\
\hline
\end{tabular}

$\mathrm{n}=$ Number of subjects, $\mathrm{SD}=$ Standard deviation, $\mathrm{BMI}=$ Body mass index, WC = Waist circumference, $\mathrm{WHR}$ = waist-to-hip ratio p-value $<0.05$ is considered statistically significant 
hyperandrogenism, decreased levels of SHBG were noted in the cases. This difference was found to be statistically significant (Table 2). Analysis of PPAR- $\gamma$ Pro12Ala polymorphism revealed the presence of CC (Pro/Pro homozygotes) in $78 \%$ of cases and $66 \%$ of controls in contrast to CG (Pro/Ala heterozygotes) which was noted only in $22 \%$ of the cases and $34 \%$ of controls. However, this difference in the genotypic distribution of $\mathrm{C} / \mathrm{G}$ genotypes was not found to be statistically significant. No GG (Ala/Ala) genotype was found in this study population. Among the allelic frequency, $52 \%$ of proline (C) was seen in cases as compared to $48 \%$ of that in controls and $39 \%$ of Alanine $(\mathrm{G})$ was seen in cases as compared to $61 \%$ of that in controls. Significantly lower PPAR- $\gamma$ levels were seen in cases as compared to controls (Table 3). A statistically significant positive correlation was seen with thyroglobulin (Tg) and PPAR- $\gamma$ in PCOS (Table 4). homeostatic model assessment (HOMA)-insulin resistance (IR) showed significant positive correlation with serum TG and negative correlation with SHBG (Table 5).
Pro/Ala heterozygotes (CG) were associated with higher insulin sensitivity as compared to Pro/Pro homozygotes (CC). The difference was however not statistically significant (Table 6). ROC curve analysis reveals PPAR- $\gamma$ as the better predictor of insulin resistance than $\mathrm{LH} / \mathrm{FSH}$ ratio, DHEAS, and HOMA-IR. (Table 7).

\section{DISCUSSION}

This study was conducted in diagnosed PCOS cases along with age-matched controls as an attempt to have a better insight into polymorphism of the PPAR- $\gamma$ gene and its possible role in the etiopathogenesis of PCOS. Regarded as a multigenic endocrine-metabolic disorder, PCOS has often been associated with dyslipidemia, obesity and insulin resistance resulting from an interplay of genetic predisposition and environmental risk factors. ${ }^{16}$ However, whether insulin resistance is causative of PCOS or a result of it is equivocal. Also, literature evidence especially Indian studies regarding polymorphism in PCOS is sparse.

Table 2: Biochemical and hormonal profile of study population

\begin{tabular}{|c|c|c|c|}
\hline Parameter & Cases $(n=50)$ Mean $\pm S D$ & Controls $(n=50)$ Mean $\pm S D$ & $p$-value \\
\hline Triglycerides $(\mathrm{mg} / \mathrm{dL})$ & $121.08 \pm 57.6$ & $97.6 \pm 44.2$ & $0.024^{*}$ \\
\hline $\mathrm{LH}(\mathrm{IU} / \mathrm{L})$ & $6.31(4.71-11.31)^{\star \star}$ & $6.61(4.39-11.34)^{\star *}$ & 0.71 \\
\hline FSH (IU/L) & $6.6(4.48-8.03)^{* *}$ & $6.72(5.1-8.4)^{\star *}$ & 0.54 \\
\hline $\mathrm{LH} / \mathrm{FSH}$ ratio & $1.03(0.60-1.67)^{\star *}$ & $1.04(0.64-1.54)^{* *}$ & 0.91 \\
\hline Prolactin (ng/mL) & $17.6 \pm 8.8$ & $20.0 \pm 8.9$ & 0.11 \\
\hline $\mathrm{FPG}(\mathrm{mg} / \mathrm{dL})$ & $87.9 \pm 1.2$ & $89.7 \pm 7.2$ & 0.22 \\
\hline Fasting insulin $(\mu \mathrm{IU} / \mathrm{mL})$ & $9.41(6.98-12.36)^{* *}$ & $8.97(6.28-14.7)^{\star *}$ & 0.97 \\
\hline HOMA-IR & $2.1(1.53-2.78)^{\star *}$ & $2.1(1.30-3.38)^{\star *}$ & 0.96 \\
\hline SHBG (nmol/L) & $50(29.5-76.5)^{\star *}$ & $79(53-151.3)^{\star *}$ & $<0.001^{*}$ \\
\hline Testosterone (ng/dL) & $38.22 \pm 6.75$ & $27.9 \pm 1.5$ & 0.29 \\
\hline DHEAS $(\mu \mathrm{g} / \mathrm{mL})$ & $3.88 \pm 1.75$ & $4.37 \pm 1.71$ & 0.18 \\
\hline
\end{tabular}

** Data represented as median (Inter quartile range) for non-parametric data

Table 3: PPAR- $\gamma$ levels in the study population

\begin{tabular}{|c|c|c|c|}
\hline Parameter & Cases $(n=50)$ Median (Inter quartile range) & Controls $(n=50)$ Median (Inter quartile range) & p-value \\
\hline PPAR- $\gamma(\mathrm{ng} / \mathrm{ml})$ & $13.16(11.78-17.08)$ & $16.05(12.07-33.0)$ & $0.04^{*}$ \\
\hline
\end{tabular}

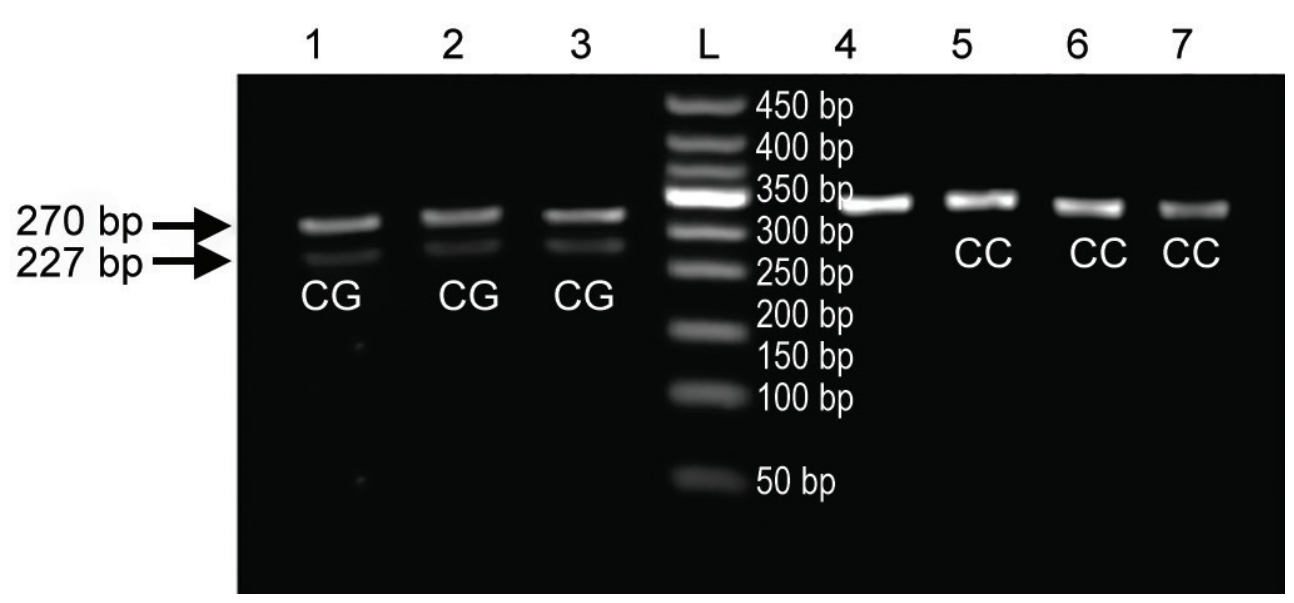

Fig. 1: Ethidium bromide stained Agarose gel used for genotyping PCR products (270 bp) with PPAR- $\gamma$ polymorphism digested with BstU1 showing 270 bp products for normal Homozygotes and 227 bp along with 43 bp products after digestion with Bst $\mathrm{U}_{1}$ 
Table 4: Correlation of PPAR-y with biochemical parameters in PCOS cases

\begin{tabular}{lll}
\hline Parameter & $\begin{array}{l}\text { Correlation coefficient } \\
\text { (r value) }\end{array}$ & $p$-value \\
\hline BMI $\left(\mathrm{Kg} / \mathrm{m}^{2}\right)$ & -0.016 & 0.913 \\
WHR & 0.029 & 0.84 \\
TG $(\mathrm{mg} / \mathrm{dL})$ & 0.295 & $0.03^{*}$ \\
SHBG $(\mathrm{nmol} / \mathrm{L})$ & -0.05 & 0.972 \\
HOMA-IR & 0.046 & 0.750 \\
\hline
\end{tabular}

Table 5: Correlation of HOMA-IR with biochemical parameters in PCOS cases

\begin{tabular}{|c|c|c|}
\hline Parameter & $\begin{array}{l}\text { Correlation } \\
\text { coefficient } \\
\text { (r value) }\end{array}$ & $p$-value \\
\hline BMI $\left(\mathrm{Kg} / \mathrm{m}^{2}\right)$ & 0.258 & 0.07 \\
\hline TG (mg/dl) & 0.304 & $0.03^{*}$ \\
\hline SHBG (nmol/L) & -0.403 & $0.004^{*}$ \\
\hline
\end{tabular}

Table 6: Inter genotypic variation based on insulin resistance (HOMA-IR) in PCOS cases $(n=50)$

\begin{tabular}{|c|c|c|c|c|c|}
\hline \multirow[b]{2}{*}{ Genotype } & \multicolumn{2}{|c|}{$(H O M A I R \geq 2.5)(n=15)$} & \multicolumn{2}{|c|}{$($ HOMA IR <2.5) $(n=35)$} & \multirow[b]{2}{*}{$p$-value } \\
\hline & $n$ & $\%$ & $N$ & $\%$ & \\
\hline CC (Pro/Pro homozygotes) & 13 & 86.7 & 26 & 74.3 & 0.33 \\
\hline CG (Pro/Ala heterozygotes) & 2 & 13.3 & 9 & 25.7 & \\
\hline
\end{tabular}

Table 7: Area under the curve

\begin{tabular}{lll}
\hline Parameter & Area & $p$-value \\
\hline PPAR- $\gamma$ & 0.605 & 0.04 \\
LH/FSH Ratio & 0.507 & 0.91 \\
DHEAS & 0.578 & 0.18 \\
HOMA-IR & 0.502 & 0.96 \\
\hline
\end{tabular}

The present study revealed significantly higher values of BMI, waist-to-hip ratio (WHR), and TG and decreased SHBG levels in cases as compared to controls (Tables 1 and 2). A similar increase in BMI and WHR in PCOS has been reported by several other studies ${ }^{17-19}$ thus further strengthening the co-existence of obesity in PCOS. The decreased SHBG levels in cases could be explained by the fact that hyperinsulinemia seen in PCOS is responsible for the high androgen concentration which in turn inhibits liver secretion of SHBG leading to its decreased levels. ${ }^{20}$ Higher TG levels in cases were in concordance with a study done on Korean women with PCOS which suggested TG to be a useful marker of insulin resistance. $^{21}$ No significant difference was noted in the LH/ FSH ratio between cases and controls in our study (Table 2). This finding is in agreement with a study conducted by Sheehan et al., ${ }^{22}$ which stated that the increased LH/ FSH ratio and hyperprolactinemia might not be necessarily associated with PCOS. The usual finding of raised $\mathrm{LH} / \mathrm{FSH}$ ratio in PCOS actually depends upon the type of PCOS phenotype. ${ }^{23}$ The present study reports significantly lower levels of PPAR- $\gamma$ in the cases as compared to controls (Table 3). The reduced levels of PPAR- $\gamma$ in cases are supportive of the fact that insulin sensitivity is related to enhanced PPAR- $\gamma$ expression. ${ }^{24}$ A significant positive correlation was found between the serum levels of PPAR- $\gamma$ and triglycerides in PCOS cases ( $p$-value $<0.05$ ) $(\mathrm{r}=0.295)$ (Table 4). A similar correlation was also reported by Semple et al. ${ }^{25}$ who proposed that PPAR- $\gamma$ enhances the lipoprotein-mediated hydrolysis of triglycerides. It also modifies triglyceride synthesis by FFA esterification via.
Acyl CoA synthase. HOMA-IR also showed a significant correlation with serum TG and SHBG (Table 5). Though HOMA-IR has been used for assessment of insulin resistance, PPAR- $\gamma$ has emerged as a major contributor to the maintenance of systemic insulin sensitivity by regulating adipogenesis and lipid metabolism. This theory is in coherence with the findings in the present study which shows PPAR- $\gamma$ to be a better marker for insulin resistance with an AUC of 0.605 in ROC. (Table 7 and Fig. 2).

Association of PPAR- $\gamma$ Pro12Ala polymorphism with PCOS has depicted variable results in different populations. This variation could be attributed to a difference in geographical distribution, ethnicity, lifestyle and sample size of the various studies conducted so far. ${ }^{26}$ Furthermore, very few Asian studies are available to decipher the role of this polymorphism in the etiopathogenesis of PCOS. Genotypic analysis revealed a relatively lower frequency of Pro/Ala heterozygotes (22\%) as compared to Pro/Pro homozygotes (78\%) in cases as compared to $34 \%$ and $66 \%$ respectively in controls (Table 3 ). Similar frequency distribution was reported by authors of several other studies in PCOS. ${ }^{26,27}$ Ala/Ala homozygotes

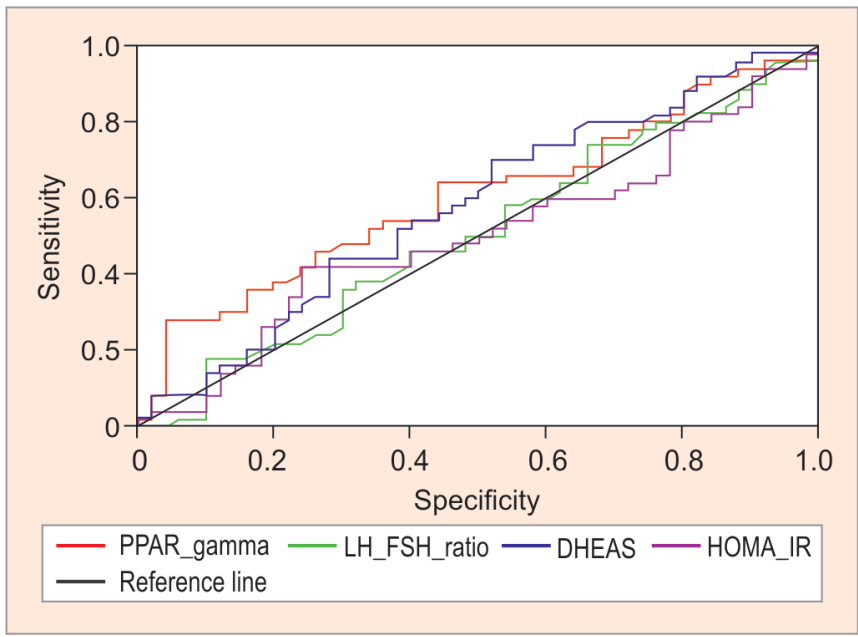

Fig. 2: ROC curve comparing various markers of PCOS 


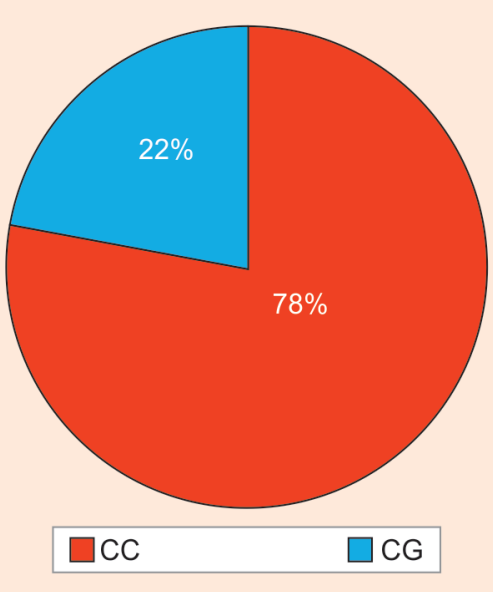

Fig. 3A and B: (A) Genotypic distribution in cases; (B) Genotypic distribution in controls

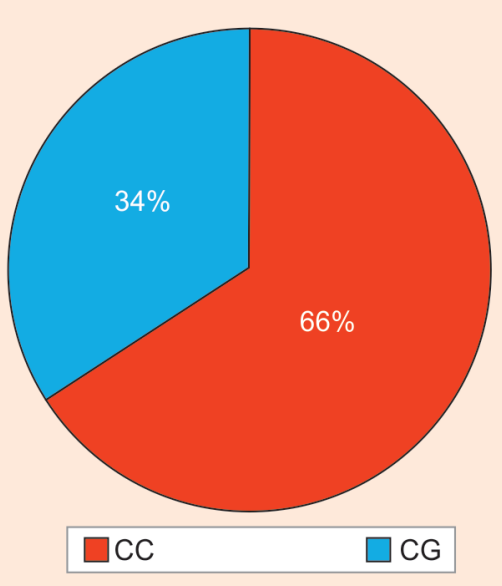

(GG) were not observed in this study. This could be due to the relatively smaller sample size of the study. Similarly, analysis of allelic frequency revealed $52 \%$ of proline (C) in cases as compared to $48 \%$ in controls and $61 \%$ of alanine $(\mathrm{G})$ in controls as compared to $39 \%$ of alanine $(G)$ in cases (p-value $>0.05$ ). However, this difference in the proportion of both genotypic and allelic frequencies was not statistically significant. ${ }^{28}$ The lower frequency of Ala in PCOS could be indicative of a possible protective effect of this genotype against PCOS as has been postulated by several authors like Korhonen et al. ${ }^{27}$ and Nuzhat et al. ${ }^{26}$

Peroxisome proliferator activated receptor $\gamma(\mathrm{PPAR}-\gamma)$ levels and their inter genotypic variation has not been studied extensively in PCOS, though Kalelioglu el al. ${ }^{29}$ reported the values of PPAR- $\gamma$ to be unequivocal between cases and control groups in a study conducted in schizophrenic male patients.

Furthermore, we also explored the association of PPAR- $\gamma$ polymorphism with characteristic features of PCOS like insulin resistance and obesity. Pro12Ala polymorphism of PPAR- $\gamma$ has been postulated to be associated with high insulin sensitivity. ${ }^{30}$ Thus, a relationship of Pro/Pro (CC) or Pro/Ala (CG) genotype with markers of insulin resistance may well be expected. However, this aspect has not been well studied in the Indian population. In the present study, Pro/Pro (CC) genotype showed a higher proportion of insulin resistance in cases comparing with Pro/Ala (CG) genotype (Table 6). But, the difference was not found to be statistically significant. A similar association was also reported by a study ${ }^{16}$ conducted in a much larger number of Caucasian women having PCOS wherein Ala carriers in PCOS group were more insulin-sensitive as compared to controls.

Although in the present study, correlation between insulin resistance and PPAR- $\gamma$ Pro12Ala polymorphism has not found to be statistically significant possibly due to relatively small sample size; but it has been found in many other studies ${ }^{26,27}$ that there is a positive correlation between insulin sensitivity and Pro/Ala (CG) and Ala/Ala (GG) genotypes. Thus, the severity of PCOS is also reduced since insulin resistance plays a quite indispensable role in the etiopathogenesis of PCOS.

\section{CONCLUSION}

The significantly reduced levels of PPAR- $\gamma$ in cases further strengthens the fact that insulin sensitivity is related to enhanced PPAR- $\gamma$ expression. PPAR- $\gamma$ has also emerged as one of the surrogate markers of insulin resistance and can be a useful tool for further understanding the etiopathogenesis of PCOS associated with insulin resistance. Incoherence with the current hypothesis suggesting a protective role of Pro/ Ala heterozygotes with higher insulin sensitivity and less obesity as compared to the Pro/Pro homozygotes. However, owing to the limitation of a relatively smaller sample size, lack of statistical significance and absence of Ala/Ala homozygotes in the present study, additional longitudinal studies in more significant sample size are recommended to elucidate the role of PPAR- $\gamma$ polymorphism in PCOS further.

\section{REFERENCES}

1. Ramanand SJ, Ghongane BB, Ramanand JB, Patwardhan MH, Ghanghas RR, Jain SS. Clinical characteristics of Polycystic Ovary Syndrome in Indian women. Indian J Endocrinol Metab. 2013;17(1):138-145.

2. Wehr E, Trummer O, Giuliani A, Gruber HJ, Pieber TR, Obermayer-Pietsch B. Vitamin D-associated polymorphisms are related to insulin resistance and vitamin D deficiency in polycystic ovary syndrome. Eur J Endocrinol. 2011 May;164(5):741-749.

3. Pasquali R, Stener-Victorin E, Yildiz BO, Duleba AJ, Hoeger $\mathrm{K}$, Mason $\mathrm{H}$, et al. PCOS Forum: research in polycystic ovary 
syndrome today and tomorrow. Clin Endocrinol (Oxf). 2011 Apr;74(4):424-433.

4. Li HWR, Brereton RE, Anderson RA, Wallace AM, Ho CKM. Vitamin D deficiency is common and associated with metabolic risk factors in patients with polycystic ovary syndrome. Metabolism. 2011 Mar;60:1475-1481.

5. Lakkakula BV, Thangavelu M, Godla UR. Genetic variants associated with insulin signaling and glucose homeostasis in the pathogenesis of insulin resistance in polycystic ovary syndrome: a systematic review. J Assist Reprod Genet. 2013 Jul;30(7):883-895.

6. Marshall JC, Dunaif A. All Women With PCOS Should Be Treated For Insulin Resistance. Fertil Steril. 2012 Jan;97(1):18-22.

7. Dunaif A. Insulin Resistance and the Polycystic Ovary Syndrome:Mechanism and Implications for Pathogenesis. Endocr Rev. 1997 Dec;18(6):774-800.

8. Molavi B, Rassouli N, Bagwe S, Rasouli N. A review of thiazolidinediones and metformin in the treatment of type 2 diabetes with focus on cardiovascular complications. Vasc Health Risk Manag. 2007;3(6):967-973.

9. Kintscher U, Law RE. PPAR $\gamma$-mediated insulin sensitization: the importance of fat versus muscle. Am J Physiol Endocrinol Metab. 2005 Feb;288(2):E287-91.

10. Tenenbaum A, Fisman EZ, Motro M. Metabolic syndrome and type 2 diabetes mellitus: focus on peroxisome proliferator activated receptors (PPAR). Cardiovasc Diabetol. 2003 Mar 23;2:4.

11. Huguenin GV, Rosa G. The Ala allele in the PPAR-gamma2 gene is associated with reduced risk of type 2 diabetes mellitus in Caucasians and improved insulin sensitivity in overweight subjects. Br J Nutr. 2010 Aug;104(4):488-497.

12. Stumvoll M, Häring H. Perspectives in Diabetes. The Peroxisome Proliferator - Activated Receptor - $\gamma 2$ Pro12Ala Polymorphism.Diabetes.2002;51(8):2341-2347.

13. Eldor R, DeFronzo RA, Abdul-Ghani M. In Vivo Actions of Peroxisome Proliferator-Activated Receptors Glycemic control, insulin sensitivity, and insulin secretion. Diabetes Care. 2013 Aug;36 Suppl 2:S162-174.

14. Zeng ZR, Leung WK, Zhou SZ, Chen B, Sung JJ, et al. Peroxisome proliferatoractivated receptor-gamma Pro12Ala polymorphism, Helicobacter pylori infection and non-cardia gastric carcinoma in Chinese. Aliment Pharmacol Ther. 2006 Jan 15;23(2):289-294.

15. Schoonjans K, Staels B, Auwerx J. Role of the peroxisome proliferator-activated receptor (PPAR) in mediating the effects of fibrates and fatty acids on gene expression. J Lipid Res. 1996 May;37(5):907-925.

16. Hara M, Alcoser SY, Qaadir A, Beiswenger KK, Cox NJ, Ehrmann DA. Insulin resistance is attenuated in women with polycystic ovary syndrome with the Pro(12)Ala polymorphism in the PPARgamma gene. J Clin Endocrinol Metab. 2002 Feb;87(2):772-775.

17. Bahcecı M, Aydemır M, Tuzcu A. Effects of oral fat and glucose tolerance test on serum lipid profile, apolipoprotein, and CRP concentration, and insulin resistance in patients with polycystic ovary syndrome. Fertil Steril. 2007 Jun;87(6): 1363-1368.

18. Sam S. Obesity and Polycystic Ovary Syndrome. Obes Manag. 2007 Apr;3(2):69-73.

19. Sharma S, Majumdar A. Prevalence of metabolic syndrome in relation to body mass index and polycystic ovarian syndrome in Indian women. J Hum Reprod Sci. 2015 Oct-Dec;8(4): 202-208.

20. Mehrabian F, Afghahi M. Can Sex-hormone Binding Globulin Considered as a Predictor of Response to Pharmacological Treatment in Women with Polycystic Ovary Syndrome? Int J Prev Med. 2013 Oct;4(10):1169-1174.

21. Park SY, Cho YJ, Lee SR, Chung H, Jeong K. Triglyceride Is a Useful Surrogate Marker for Insulin Resistance in Korean Women with Polycystic Ovary Syndrome. Yonsei Med J. 2015; 56(3):785-792.

22. Sheehan MT. Polycystic Ovarian Syndrome:Diagnosis and Management. Clin Med Res. 2004 Feb;2(1):13-27.

23. Al-Jefout $\mathrm{M}$, Alnawaiseh $\mathrm{N}, \mathrm{Al}-\mathrm{Qtaitat} \mathrm{A}$. Insulin resistance and obesity among infertile women with different polycystic ovary syndrome phenotypes. Nature. 2017 Jul;7:5339 DOI:10.1038/s41598-017-05717-y.

24. Jiang X, Ye X, Guo W, Lu H, Gao Z. Inhibition of HDAC3 promotes ligand independent PPAR $\gamma$ activation by protein acetylation. J Mol Endocrinol. 2014 Oct;53(2):191-200.

25. Semple RK, Chatterjee VK, O'Rahilly S. PPAR gamma and human metabolic disease. J Clin Invest. 2006 Mar;116(3): 581-589.

26. Shaikh N, Mukherjee A, Shah N, Meherji P, Mukherjee S. Peroxisome proliferator activated receptor gamma gene variants influence susceptibility and insulin related traits in Indian women with polycystic ovary syndrome. J Assist Reprod Genet. 2013 Jul;30(7):913-921.

27. Korhonen S, Heinonen S, Hiltunen M, Helisalmi S, Hippeläinen M, Koivunen R, et al. Polymorphism in the peroxisome proliferator-activated receptor-gamma gene in women with polycystic ovary syndrome. Hum Reprod. 2003 Mar;18(3):540-543.

28. Dasgupta S, Sirisha P, Neelaveni K, Anuradha K, Sudhakar G, Reddy BM. Polymorphisms in the IRS- 1 and PPAR- $\gamma$ genes and their association with polycystic ovary syndrome among South Indian women. Gene. 2012 Jul 15;503(1):140-146.

29. Kalelioglu T, Durak N, Karamustafalioglu N, Genc A, Akkus $\mathrm{M}$, Tasdemir A et al. Serum peroxisome proliferator-activated receptor gamma levels in acute phase of male patients with schizophrenia and their relationship with metabolic parameters. Bull.Clin.Psychopharmacol. 2017;27(1):30-34.

30. Bhatt SP, Misra A, Sharma M, Luthra K, Guleria R, Pandey RM et al. Ala/Ala Genotype of Pro12Ala Polymorphism in the Peroxisome Proliferator-Activated Receptor- $\gamma 2$ Gene is Associated with Obesity and Insulin Resistance in Asian Indians. Diabetes Technol Ther. 2012;14(9):828-834. 